\title{
FLASH FLOOD MAPPING FOR MOUNTAIN STREAMS USING HIGH-RESOLUTION ALOS-2 DATA
}

\author{
Young-Joo Kwak* \\ International Centre for Water Hazard and Risk Management (ICHARM-UNESCO), Public Works Research Institute (PWRI) 1-6 \\ Minamihara, Tsukuba, Japan 305-8516 - kwak55@ pwri.go.jp
}

Commission VI, WG VI/4

KEY WORDS: ALOS-2, Capacity building, Flood detection, Valley floodplain

\begin{abstract}
:
This paper introduces a practical way to improve the risk management capacity and resilience of communities by utilizing a prompt flash flood map produced from very high spatial resolution ALOS-2 data. An improved flood detection algorithm is proposed to achieve a better discrimination capacity to identify flooded areas in the valley floodplain based on cluster analysis by verifying training sites and understanding pixel-based backscattering behaviour focusing on surface roughness changes caused by floodwater and floating debris, i.e., mud flow with gravels, stones and uprooted trees. The results show the possibility of a rapid, straightforward change detection approach to flood mapping, in particular to identify and classify floodwaters, damaged buildings, damaged rice fields, and stacks of driftwood through evidenced-based investigation.
\end{abstract}

\section{INTRODUCTION}

\subsection{Background}

Japan continually suffers intensive damage from natural disasters, such as earthquakes, landslides, and floods. Despite the Japanese government's strategic efforts under a national framework to mitigate disaster risk, many local governments have not been able to increase risk management capacity, and had a hard time implementing effective ways to mitigate disaster risk and enhance risk resilience. The improvement of risk management capacity and resilience of communities has been recognized as a priority issue for the Japanese government.

Earth observation-based disaster emergency response is one of the best and powerful tools for better disaster monitoring and risk management. Utilizing the advantages of optical and satellite synthetic aperture radar (SAR) sensors, satellite applications should be designed to maximize sensor capabilities (Kwak, 2017). In particular, SAR is superior to optical sensors in detecting flood inundation areas, because of a high spatial resolution with near-all-weather and all-day operating capabilities. For example, when a flash flood occurred in a valley-bottom stream surrounded by mountains, optical sensors cannot detect in time inundated and damage areas accurately due to a typhoon with torrential rain and cloud.

As the Japan Aerospace Exploration Agency (JAXA) is carrying out emergency operation using the single polarization $(\mathrm{HH})$ with a ultra-fine mode (UBS: SM1) as the highest priority mode, single-polarization processes play a very important role in emergency response to provide prompt risk information, i.e., flood maps. In line with this emergency strategy, flash flood mapping based on information from SAR is an only way to deliver risk information right after flooding, despite low accuracy due to difficulties in pre-processing and interpreting SAR images. When it comes to determining the evacuation time and issuing early warnings, rapid flood mapping is one of the most important components in emergency response right after flooding, in particular to figure out and report overall flood risk and flood damage status to decision makers and stakeholders, such as local agencies, risk managers, civilians living in risk zones. Therefore, the Japanese government strongly request JAXA to utilize and maximize Advanced Land Observing Satellite-2 (ALOS-2) application. The prompt mapping products of flash flood with maximum inundation extent are a core component to assess physical flood risk in order to understand overall flood situation. In addition, rapid flood maps produced from very high spatial resolution ALOS-2 images (i.e., 3 meters) can be useful resources to learn high-risk flood zones (hotspots) from a record-braking flood event in order to improve resilience of communities. Besides the flood mapping accuracy associated with prompt processing (based on insufficient ground validation and model calibration), prompt flood detection is a sequential process to estimate flood risk proxy such as human losses and economic losses, i.e., building and infrastructure damages and agricultural damages. The prompt proxy mapping of flood risk will be provided rapidly in any weather condition for any place in a floodplain as well as in a mountainous valley-stream network.

\subsection{Objective}

To improve the flood algorithm and the accuracy of flash flood mapping from very high spatial resolution ALOS-2 data, this study investigated the characteristics of backscattering changes on the double bounce effect, which is affected by floodwater surface and surface roughness. In this paper, a new flood detection algorithm was employed to produce a prompt flood map focusing on surface roughness changes induced from floodwater and floating debris, i.e., mud flow with gravels, stones and uprooted trees in the case of the 2016 Omoto River flood in a valley-bottom plain in Japan. In general, a flood detection algorithm considering only the behaviour of water 
surface backscatter cannot discriminate flood-affected pixels accurately from flood damage areas; however, the new algorithm is designed to detect damage areas from building areas, rice paddy fields, and floodplain areas after the flood has receded. The main concern is to determine optimal criteria as global split-threshold from variation in backscattering intensity on surface complexity in verified training sites. The proposed algorithm can support emergency flood disaster response so that a local community will be able to implement evidence-based operational flood risk management.

\section{STUDY AREA AND DATA SET}

\subsection{Study Area}

On August 30, 2016, a strong typhoon No. 10 hit northeastern Japan with a record-breaking rainfall of $62.5 \mathrm{~mm} / \mathrm{h}(250$ $\mathrm{mm} /$ day). Many landslides and floods occurred mainly along valley-bottom streams in granitic and slate watersheds, accompanied by landslides (debris flows) and floating debris, i.e., trees uprooted from a thin surface soil layer on the granitic hill slope about $0.5 \mathrm{~m}$ thick. Iwate Prefecture (2016), the most damaged Prefecture in Japan, reported that the typhoon caused economic losses as much as 1.3 billion dollars in damage, damaged 2700 buildings, and left 21 dead and 4 missing, which made the disaster the worst in history. A representative station of the Omoto River reported that the record-breaking river water level, the flood peak, exceeded the levee height, reaching 7 meters at 20:00 p.m., August 30, 2016 (Japan time). The Omoto River was selected as the pilot study, a valley-bottom stream about $65 \mathrm{~km}$ long with a basin area of $731 \mathrm{~km}^{2}$. It is managed by Iwate Prefecture, and $75 \%\left(11000 \mathrm{~km}^{2}\right)$ of its surrounding area is covered by forests. Figure 1a shows ALOS User Interface Gateway (C) AUIG 2016, JAXA) for officially registered end users to request acquired ALOS data. The selected study area, which lies between latitude $39.825^{\circ}$ $39.858^{\circ} \mathrm{N}$ and longitude $141.75^{\circ}-141.99^{\circ} \mathrm{E}$, covers the area from the valley floodplain to the river mouth of the Omoto River (indicated in the white box on yellow antenna's footprint) in Figure 1b.

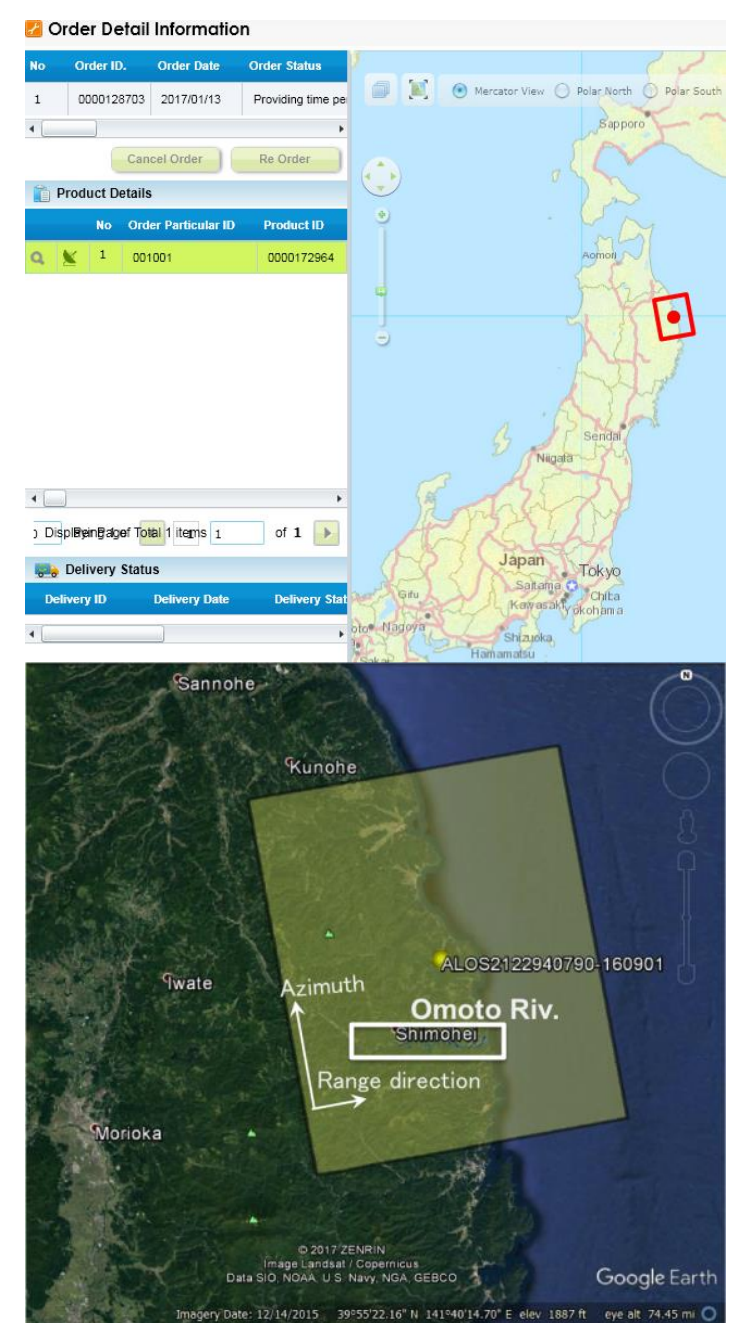

Figure 1. ALOS User Interface Gateway (C) 2016 ALOS-2 Image Copyright, JAXA) and selected study area (ㄷ 2018 Google)

\subsection{Data Used}

Under the emergency observation rules, JAXA successfully acquired very high spatial resolution (SM1) L-band SAR (PALSAR-2) data and released a processing level of 3.1 (geocoded in map projection, UTM zone 54 north, Ellipsoid: WGS84). The author mainly used multi-look complex data acquired before and after the flood at 22:56 p.m. (Japan time) on November 12, 2015, and July 31 and September 1, 2016. Table 1 shows employed ALOS- 2 data on the area in antenna's footprint in the red rectangular (Figure1a) with three different time acquisitions provided from AUIG (ALOS-2/ALOS User Interface Gateway (C) ALOS-2 Image 2016, JAXA). Next, for investigating pre-flood ground roughness, the precise digital elevation model (DEM) data was collected by the airborne LiDAR (Laser Imaging Detection and Ranging) and released by the Geographical Information Authority of Japan (GSI). The LiDAR-based DEM has a five-meter spatial resolution with centimetre height resolution. For the validation of flood areas, ground truth data were collected by conducting field survey, and air-photo images were sUAV-captured after the flood on September 11, 2016 (CGSI) and by the author on November 29 , 2017 , one year after the restoration of rice paddy fields in the valley floodplain. 


\section{RESULTS}

This preliminary study, as an effort in emergency response, presented a flash-flood mapping approach to risk management for enhancing the risk management capacity and resilience of communities. This approach enables a simple, prompt statistical-based change detection to identify satellite-detected flood inundation areas and damage areas in valley floodplains at a reasonable level of accuracy.

\subsection{Limitation of pre-processing SAR images}

Although ALOS-2 level 3.1 images are geocoded with quality corrections (e.g., noise reduction and dynamic range compression), distance errors still remain particularly along a river line (JGD 2011). This has been a critical issue to achieve highly accurate spatial-data processing since the launch of ALOS. The distance error along the river line to the intersecting alignment was greater than that to the range direction (west to east in Figure 1a), with an error being as great as 70 meters (approximately equivalent to over 10 pixels) due to geometric distortion. In order to integrate GIS data, distortion error correction should be conducted and re-projected accurately by means of terrain-corrected and geocoded ALOS-2 data using more accurate DEM (@GSI).

\subsection{Statistical split-threshold optimization}

In general, the variation of floodwater over a wide-open area and flooded rice fields was significantly decreased. There are many unexpected and ambiguous backscatter behaviours due to various types of surface complexity and heterogeneity; in addition, backscattering behaviour varies widely even in the same class. In this experimental training site, the representative five classes were introduced to describe backscattering variations in flood-affected areas as the criteria of global threshold shown in Table 2. The difference in backscattering intensity of floodwater between pre- and post-flood was significantly decreased from $10.0 \mathrm{~dB}$ to $-20.1 \mathrm{~dB}$ due to specular reflection from water surface. The maximum difference was about $30 \mathrm{~dB}$ and the mean value of the difference decreased by about $-12 \mathrm{~dB}$. On the contrary, the difference in surface change, i.e., sand bar and stacks of driftwood from floating debris, significantly increased from near $0 \mathrm{~dB}$ to $+12.4 \mathrm{~dB}$ due to double bounce. The maximum difference was about $9.3 \mathrm{~dB}$ and the median value of the difference increased by about +4.9 $\mathrm{dB}$.

\begin{tabular}{|c|c|c|c|c|}
\hline & \multicolumn{2}{|c|}{ Increase $(\mu: \mathrm{dB})$} & \multicolumn{2}{|c|}{ Decrease $(\mu: \mathrm{dB})$} \\
\hline Flooded classes & $++\Delta$ & $+\Delta$ & $-\Delta$ & $--\Delta$ \\
\hline Floodwater & \multirow{5}{*}{\multicolumn{2}{|c|}{$\begin{array}{l}0.4(+0.3) \\
4.2(+1.9)\end{array}$}} & \multirow{5}{*}{$2.5(+1.9)$} & \multirow{4}{*}{$12(-4.9)$} \\
\hline Building & & & & \\
\hline Sand bar & & & & \\
\hline Drift wood & & & & \\
\hline Paddy field & & & & $10.4(-1.4)$ \\
\hline
\end{tabular}

Table 2. Backscatter characteristic of the selected flood-affected classes in training site
As a result of the analysis of surface roughness changes, Figure 3a shows a geomorphic change on a flat sand bar, which was categorized in the paddy field class, at a levee break in this study (C) 2016, Google). Figure 3b shows ALOS-2 composite images in different times before and after the flood (RGB composite, Red: pre-flood on Jun 9, 2016, Green: pre-flood on December 11, 2015, Blue: post-flood on September 1, 2016 () JAXA). The blue and yellow pixels indicated a considerable change in backscattering intensity of floodwater and potential damage areas.

Figure $3 \mathrm{c}$ shows the sensitivity of backscatter intensity to micro-topography undulation on the sand bar. The backscattering spreads irregularly in the elevation range of 2.5 meters between $15.5 \mathrm{~m}$ and $18.0 \mathrm{~m}$ (the green and red dots in Figure 3c). After severe surface change due to the flash flood and floodwater, the mean value (the blue dot in Figure 3c) showed an overall increase from $-1.8 \mathrm{~dB}$ to $2.4 \mathrm{~dB}$. In addition, Figure $3 \mathrm{~d}$ shows the PDF-based backscatter variation interpreted by surface roughness change. Despite of the various backscattering behaviours on a flat sand bar, two normal distributions of PDF (the green and red lines in Figure 3d) were very similar even with a seven-month gap between December 2015 and June 2016, while the PDF (the blue line in Figure 3d) was sharper and higher after the flood than the two distributions. According to the backscatter characteristics, a statistic variable $( \pm)$ became optimal criteria as a global split-threshold value in case of ground roughness change.

\subsection{Prompt flash flood map}

For prompt flash flood mapping, pixel-based change detection and the correlation coefficient of the backscatter intensity were applied to identify flood inundated areas and damaged areas. Figure $3 \mathrm{e}$ shows the resultant overall flood map of the valley floodplain mainly in the lower Omoto River below 50 meters in elevation with a mild river slope of 1:300. The blue pixels indicate floodwater, where the backscattering variation decreased significantly by over $-5 \mathrm{~dB}$ while the red pixels indicate damaged areas, where the backscattering variation increased significantly by over $+3 \mathrm{~dB}$ due to surface changes.

\subsection{Validation}

For the validation of flood-affected areas, ground truth data were used to compare actual inundated areas with ALOS-2detected inundation areas. Part of the ground truth data were collected by a small unmanned aerial vehicle (sUAV: Quadcopter with a flight control system, (C) DJI Technology Co. Ltd., China). Figure 4 compares airphotos of the sUAVcaptured actual flood-affected areas during the flood (Figure 4a (C) September 11, 2016, GSI) and one year after restoration (Figure 4b () November Nov 29, 2017, ICHARM). According to field inspections, most of the flood-affected areas in Figure $3 \mathrm{e}$ (red color pixels) indicate geomorphologic and volumetric changes occurred, resulting in minor to major surface deformation. The author confirmed that the significant increase of backscatter intensity (red color pixels in Figure 3e) was mainly caused by the surface changes formed by overflows and debris flows, i.e. sand, gravel and driftwood. 
(a)
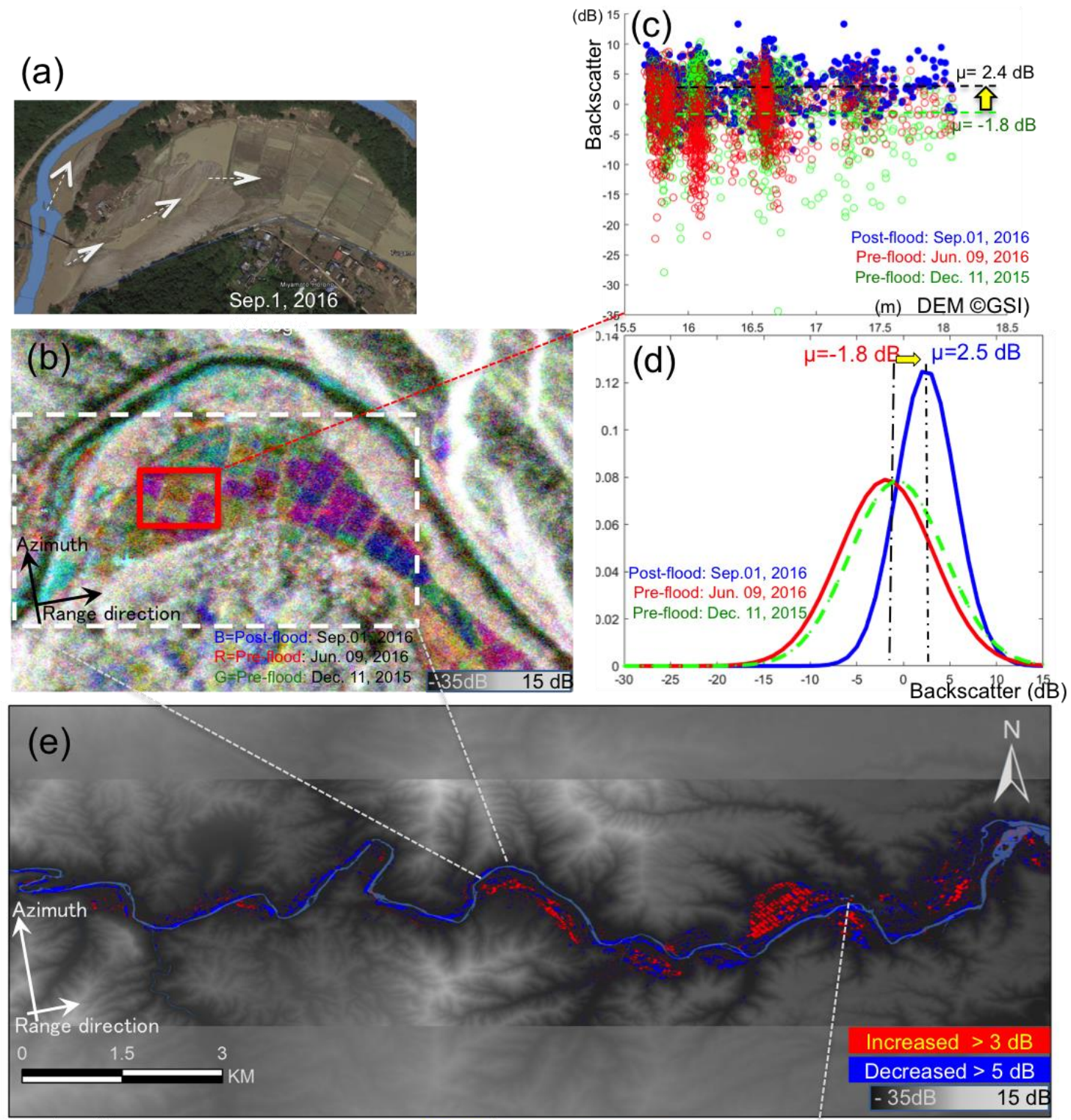

(f)

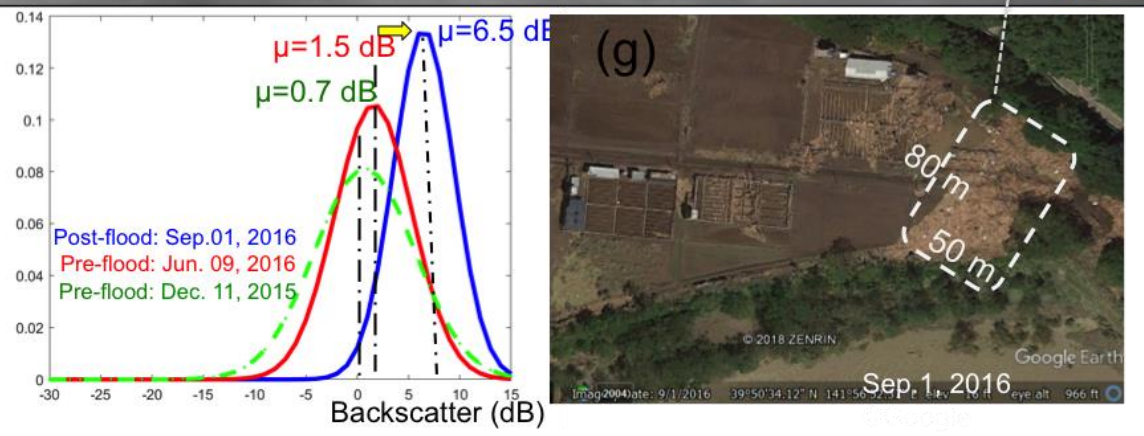

Figure 3. Experimental statistical analysis and flood map in Omoto River; (a) sand bar near the levee breach in sampling site (C) September 1, 2016, Google), (b) ALOS-2 amplitude images (R: pre-flood on Jun 9, 2016, G: pre-flood on December 11, 2015, B: post-flood on September 1, 2016), (c) backscattering plots between variation and DEM (C GSI), (d) distribution of PDFs in sand bar, (e) overall flash-flood map, (f) distribution of PDFs in stacks of driftwood, and (g) stacks of driftwood in sampling site (C September 1, 2016, Google) 


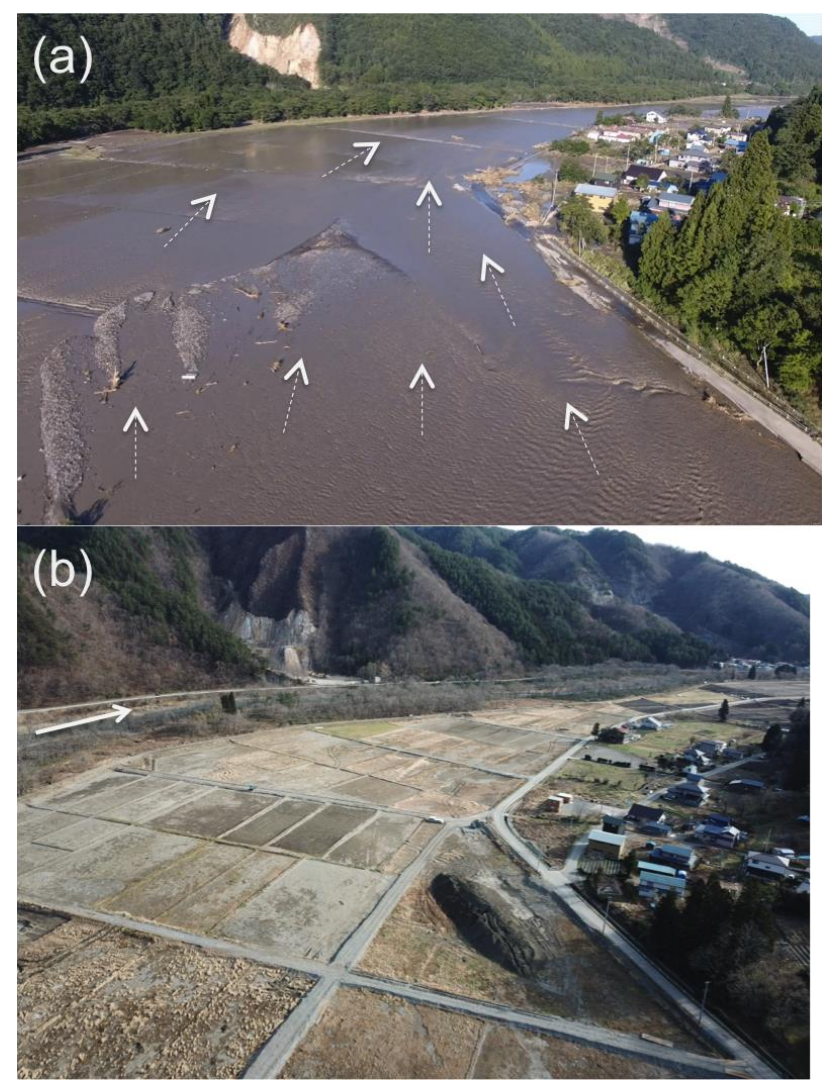

Figure 4. Comparative sUAV-captured airphotos during flood (C) September 11, 2016, GSI) and after one year restoration (C) November 29, 2017, ICHARM)

\section{DISCUSSION}

The author's findings were summarized and discussed focusing on the surface and double bounce scattering effects in the single-polarization $(\mathrm{HH})$ data processing as follows:

First, as an accurate pre-processing of SAR, geometric correction and speckle noise reduction are essential preconditions for accurate, prompt flash-flood mapping for a valley floodplain lying along the lower Omoto River.

Second, the author investigated the characteristics of the backscatter variation in the valley floodplain using a statistical split-threshold approach. For accurate, prompt flash-flood mapping, backscatter intensity should be investigated more carefully by conducting not only two-period comparison before and after the flood but also time-series spatio-temporal change analysis. However, because of time difference between emergency observation and an actual flood event, accurate flash flood detection is extremely difficult at this moment.

Besides the limitations of single polarization, there are many challenging issues to be solved for more accurate flood mapping in the future; for example, comparative studies of backscattering changes with different incidence angle, object orientation, segment length, and height influenced by surface roughness, particularly regarding high-density residential and commercial zones without validation data.

Finally, when it comes to accomplishing more credible risk information with higher accuracy, the application of ALOS-2 data should be more widely promoted for nationwide monitoring, as well as calibration and validation of hydromodel simulation to compare simulated and actual flood inundation at the flood peak.

\section{CONCLUSION}

To improve the risk management capacity and resilience of communities without sufficient risk information, the author proposed a statistical split-threshold method for supervised and unsupervised flash-flood detections to identify flood inundated and damaged areas. The resultant flood map shows the possibility of a rapid, straightforward change detection method to flash flood mapping, in particular to identify floodwaters, damaged buildings, damaged rice fields, and stacks of driftwood through evidenced-based investigation. The trial prompt flash flood map will be continually updated to overcome insufficient accuracy and data limitations. Moreover, this feasibility study found that the ALOS-2-derived proxy maps can be applied to integrate risk information data as the subsequent flood risk and damage data (i.e., damage to buildings, infrastructure, and rice crop in the flooded area) at any scale and with any kind of pixel-based calculation for operational risk management and emergency response. Satellite-based emergency mapping should be widely applied to all levels of a flood risk management community as communication tools to implement the best practice to build safe societies and strengthening communities through periodical evacuation drills.

\section{ACKNOWLEDGEMENTS}

This study was supported by the Japan Society for the Promotion of Science (JSPS) KAKENHI Grant-in-Aid for Scientific Research B: 15H05136. We thank JAXA for providing ALOS-2 data from emergency observation and GSI for providing digital data and in-situ data from field survey.

\section{REFERENCES}

Geospatial Information Authority of Japan (GSI), 2015. Available: http://www.gsi.go.jp

Iwate Prefecture, 2016. News from Iwate's reconstruction, https://www.pref.iwate.jp/kokusai/27900/35196/049755.html

Kwak, Y. 2017. Nationwide Flood Monitoring for Disaster Risk Reduction Using Multiple Satellite Data, ISPRS Int. J. Geo-Inf. 6, pp. 203-215 https://doi:10.3390/ijgi6070203

Kwak, Y., Yun, S., Iwami, Y., 2017. New Approach for Rapid Urban Flood Mapping Using ALOS-2/PALSAR-2 in 2015 Kinu River Flood, Japan, International Geoscience and Remote Sensing Symposium (IGARSS) 2017 IEEE International, pp.1880-1883

https://doi:10.1109/IGARSS.2017.8127344

Martinis, S., André Twele, and Stefan Voigt, "Unsupervised Extraction of Flood-Induced Backscatter Changes in SAR Data Using Markov Image Modeling on Irregular Graphs", IEEE Trans. Geosci. Remote Sens., 49(1), 251-263, 2011.

Otsu, N. 1979. A threshold selection method from gray-level histograms", IEEE Trans. Syst., Man, Cybern., vol. SMC-9, no.1, pp. 62-66.

Rignot, E. and Van, Zyl J., 1993. Change detection techniques for ERS-1 SAR data, IEEE Trans. Geosci. Remote Sens., vol. 31, no. 4, pp. 896-906

Revised Feburary 15, 2018 